\title{
Paternalistic Care and Transformative Recognition in International Politics
}

\author{
Fiona Robinson
}

In this chapter, I address what Uma Narayan described in 1995 as 'the selfserving collaboration between elements of colonial rights discourse and care discourse' (1995: 133). Narayan argues that, in general terms, the colonizing project was seen as being in the interests of, for the good of and as promoting the welfare of the colonized (1995: 133). She suggests further that these notions draw our attention to the existence of a 'colonialist care discourse' whose terms have some resonance with those of some contemporary strands of the ethic of care (1995: 133).

For about three decades, feminist philosophers and political theorists, including care ethicists, have been preoccupied with developing a sustained critique of various aspects of liberal individualism. As found in otherwise diverse moral and political philosophies including contract, rights-based and neoKantian theories, the individual moral agent has been criticized by feminists as disembodied, disembedded, self-interested and abnormally self-reliant (Walker 1998: 7, 131). This picture of the individual - flawed as both a description of reality and a normative ideal - has been criticized as being contrary to the experiences of most women. Feminists argue that this picture both ignores and obscures the 'often unchosen, discretionary responsibilities of those who care for particular others, often dependent and vulnerable, in intimate, domestic or familial - "private" - contexts' (Walker 1998: 51).

In many ways, it is not surprising that feminist critique has been centred on 'autonomous man', 'that centerpiece of modern Western culture and protagonist of modern moral philosophy', and the discourses of rights and justice in which he is said to engage (Walker 1998: 131). But Narayan's analysis disturbs the feminist dichotomy between rights-holding autonomous man and the relational 
subject. Narayan points out that the rights-discourse - the contractual focus on relationships between equals, and on agents as independent, separate and mutually disinterested - was only part of the liberal story. Another part was that these same subjects had paternalistic obligations and responsibilities to 'inferior Others', whether women in their own families or distant colonial peoples (Narayan 1995: 135). She suggests that while aspects of contemporary care discourse have the potential virtue of calling attention to vulnerabilities that mark relationships between differently situated persons, care discourse also runs the risk of being used to ideological ends where these 'differences' are defined in self-serving ways by the dominant and the powerful (Narayan 1995: 136).

Care ethicists, of course, have not been blind to this danger. Especially as the ethics of care has spread beyond the realms of moral psychology and ethics to political theory, care ethicists have been particularly aware not only of the progressive potential of care ethics, but of the very real possibilities for domination that inhere. Thus Joan Tronto has suggested, 'There is always implicit in care the danger that those who receive care will lose their autonomy and their sense of independence' (Tronto 1993: 146). Because care ethicists are concerned to highlight moral (and political) relations of unequal power (and to point out that, in fact, this is what most moral and political relations actually look like), they cannot escape the possibility that 'caring' may end up looking more like domination. Marian Barnes (2012: 6-7) calls this the 'dark side' of care, and insists that it is important to acknowledge that much of what has been called 'care' in a variety of different contexts has been and remains associated with practices that are anything but 'caring. Within the literature on care and domestic social policy, the most powerful critiques of this nature have come from within the disability movement. In fact, the word 'care' itself has become virtually lost from social work discourse, replaced by an emphasis on 'choice and control' as key values (Barnes 2012: 6).

Of course, practices of care among, say, mothers and children, or differently abled individuals and those who assist them, are very different from the relations and responsibilities of care that we normally consider to be most relevant to global politics. That said, if we are prepared to accept that questions about how we care for one another in the world are important questions for the theory and practice of international relations, then we must also accept the very real possibility that some self-described care is, in fact, 'bad care' (Barnes 2012: 7) and that the language of 'caring about' distant others is often used as a justifying discourse for ideological ends. While Narayan refers to the use of this language in the context of modern colonialism, its relevance extends beyond the period 
of formal imperialism of the nineteenth and twentieth centuries. Indeed, discourses of 'care' in international politics have been used regularly to justify paternalistic acts of domination through the use of structural and physical violence - in the treatment of indigenous peoples, the 'protection' of women and children in warfare, and in the practices of contemporary humanitarianism, including humanitarian interventions. As Michael Barnett (2013: 486) argues, however much humanitarian governance is propelled by an emancipatory ethic and the siren of humanity, it also contains elements of domination.

This paper asks whether a global ethic of care - as a normative roadmap for relations among actors within and beyond borders - can escape the spectre of paternalism. What would it really mean to take seriously the problem of paternalism in global politics? Would it mean abandoning an ethic of care entirely? Is there a way of ensuring that practices of care involve listening to and hearing the authentic voices of all persons, so that care avoids eclipsing the other, or inhibiting the ability of the 'cared for' to be self-determining - to make their own decisions, to live their lives as they choose? Presumably, this would mean ensuring that the 'other-regarding' nature of care involved not only acting to address the needs of the other, but acting to recognize the other as a person in her own right. In other words, it would involve integrating the ethics of care into an account of moral recognition.

At first glance, it would seem that the nub of the problem here concerns the opposing normative importance placed on the concepts of autonomy and vulnerability in the theories of recognition and care, respectively. Care ethics are widely lauded for their attention to mutual vulnerability and interdependence. Moral agents should be seen as embodied, frail and interdependent; exposing the ubiquity and centrality of care practices reveals the mutual vulnerability of all human beings. By contrast, autonomy is widely seen as a key element of 'recognition' - in other words, recognition must be seen as a necessary aspect of justice because it ensures autonomy - including both group and individual autonomy. In the international context, quests for political, legal and moral recognition all seem to be grounded in aspirations to autonomy and identity (Bartelson 2013: 124). Again, by contrast, care ethicists, and feminist theorists who are sympathetic to care ethics, have either rejected the (liberal) notion of autonomy, or have sought to 'rethink' it, most notably through the idea of 'relational autonomy'. But in rejecting or even in revising the liberal understanding of autonomy, are care ethicists dispensing with a vital concept that is a necessary prerequisite of justice - especially transnational or global justice? Is a thoroughgoing account of recognition a necessary part of a global ethic of 
care precisely because it can guard against paternalistic care, and ensure the maintenance, development or retrieval of autonomy on the part of groups that are the 'receivers' of care - the 'global poor', the 'developing world', 'the global south'?

In this chapter, I start from the position articulated by Bartelson that, far from ensuring autonomy and moral equality, recognition in international relations has functioned primarily as a mechanism for excluding and marginalizing peoples who do not already meet the criteria for recognition. In this way, dominant theories and practices of recognition are also guilty of paternalism, insofar as they have served to uphold Western standards of civilization (Bartelson 2013: 123). I will argue that, in contrast to much of the literature on justice as recognition, which emphasizes the need for powerful or dominant voices to 'recognize' the ways of life of marginal groups, recognition in the context of relations of care must involve an unsettling of the categories of those who 'bestow' care and recognition, and those who receive them. Here I borrow from the work of Marian Barnes, who uses Nancy Fraser's notion of 'transformative recognition' as a basis for a 'politics of care' (Barnes 2012: 178). As Barnes explains, Fraser draws a distinction between 'affirmative' remedies to injustice and 'transformative' ones. On this view, transformative recognition would require strategies designed to disturb and challenge widely held assumptions about the roles of 'carer' and 'cared for'. Barnes explains how, in the context of social policy of European welfare states, this approach has the potential to destabilize categorizations that lead to competitive constructions of political objectives based in separate identities (Barnes 2012: 179).

In what follows I will develop the idea of transformative recognition in the context of a global political ethic of care. In so doing, I will seek to highlight two key points. First, I will argue that simply invoking the idea of 'recognition' is no guarantee that the autonomy of all those involved will be upheld. In fact, it is quite plausible that the exact opposite is true. As Bartelson (2013: 121) argues, while theories of recognition seek to account for the inclusion of actors into some larger sociopolitical whole, the actual mechanisms for recognition have simultaneously served to exclude certain actors from membership, and thus deny their autonomy. Recognition is not meaningful if it involves powerful agents recognizing a version of the other that has little relation to who or what they are, or if it involves the 'production' of others as subjects whose existence serves to support or uphold existing, unequal relations of power. In a postcolonial world rife with development projects and strategies and anti-poverty campaigns, both 'caring for' and 'recognizing' distant others are potentially little more than discursive practices that produce particular kinds of subjects that serve the ends of the already-powerful. 
If the concept of recognition is going to mitigate the paternalistic tendencies of care ethics, it will have to look quite different from the way in which it has been theorized and practised in international relations thus far.

For this reason, strategies of transformative recognition that support a global politics of care must involve sustained analysis of what Narayan calls the 'accounts' that are given of the interdependencies and relationships which are so crucial to an ethic of care (Narayan 1995: 136). Notions of differences in vulnerabilities and capabilities, Narayan argues, should be recognized as contested terrain, requiring critical attention to who defines these differences as well as their practical implications (Narayan 1995: 136; emphasis added). This brings me to my second point: that strategies of transformative recognition must involve attention to the politics of representation. By this I do not mean representation in the formal political sense, centred on issues of membership and procedure (Fraser 1995). Rather, I mean the political act of discursive framing and construction of subjects in order to serve specific ends - in this case, to serve the ends of 'development', 'humanitarianism' or 'care'.

Strategies of transformative recognition demand reflection upon the ways in which the discursive structure of injunctions to 'care about' distant others may serve to reinforce dichotomous and hierarchical categories of 'carers' and 'cared for' in the world. Recognition that is transformative questions and disturbs this basic structure in an effort to transform, rather than reinforce, existing inequalities. On this view, the function of recognition is not so much to recognize and ensure the autonomy of individuals and groups, but rather to ensure that their agency is not constrained or effaced, and that their voices are heard. Transformative recognition ensures that practices are based on a picture of mutual vulnerability and interdependence, and a shared need both to care and be cared for.

This chapter is divided into three parts. In the first part, I will briefly outline the central ideas of both the ethics of care and the theory of recognition, focusing on the similarities, relations and points of intersection between the two approaches. This section will also address the (relatively scant) work that considers care ethics and recognition in the context of international politics, demonstrating the limitations of their dominant or conventional readings in this context. The second part will return to the problem of paternalism in care ethics, focusing specifically on the contemporary contexts of development and humanitarianism. Finally, part three will elaborate on the idea of strategies of transformative recognition, focusing specifically on how these ideas may be integrated to create a more complete account of a global ethic of care which mitigates the dangers of paternalism and domination. 


\section{The ethics of care and the ethics of recognition}

The ethics of care is a relative newcomer in the field of ethics, but it has gained remarkable traction, especially in the past two decades. Care ethics presents a radical challenge to dominant, rationalist approaches. It is an account of ethics which sees the basic substance of morality as located in the dispositions and practices of caring which feature so significantly in the day-to-day lives of most people around the world. Care ethics starts from a notion of the self as fundamentally constituted by and through relations with others. Care ethics is constituted not by rules or principles, but through practices. In contrast to the masculinist moral subject constructed by rationalist ethics - autonomous, self-willing, governed by reason - care ethicists see moral subjects as naturally vulnerable and mutually dependent. Care ethics emphasizes embodiment and human frailty, and argues that our shared needs to receive and give care should be seen as starting points for thinking about ethics, rather than as merely private and thus irrelevant.

While the ethics of care is normally traced to the work of moral psychologists, especially Carol Gilligan (1982), over the past three decades the idea of 'care' has been taken up by political philosophers and social theorists. Political theorist Joan Tronto's book Moral Boundaries: A Political Argument for an Ethic of Care set the stage for the development of a rich literature on the politics of care. In that book, Tronto (1993: 3) explicitly rejects the idea of care as a 'women's morality', but affirms that it is an approach to ethics that 'includes the values traditionally associated with women'. She explains, 'questions of natality, mortality, and the needs of humans to be cared for as they grow up, live, and die, have not informed the central questions of philosophers.... Theorists' exclusions operate forcefully to set boundaries between those questions and concerns that are central and those that are peripheral' (Tronto 1993: 3-4). Due, in large measure, to this explication of the political implications of care, interest in care ethics has increased rapidly across disciplinary divides. No longer confined to moral philosophy, studies in the ethics of care can now be found in political theory, geography, environmental studies, peace research, social work and social policy, education studies and political economy. Only very slowly, however, is it advancing into the field of International Relations (see Hutchings 2008; Porter 2007; Robinson 1999, 2011).

The contemporary theory of 'recognition' also, notably, grew up in response to dominant normative political theories. But this time it was not rationalist universalist moral theory as such, but the widespread Western consensus on 
theorizing about justice which focused on the imperative to remove any form of social or economic inequality that could not be justified on rational grounds' (Honneth 2001: 43). Seeking to move beyond the myopic focus on distributive justice, recognition theorists developed an understanding of justice whose normative aim was not the elimination of inequality but the avoidance of degradation and disrespect, towards the achievement of the 'recognition of the personal dignity of all individuals' (Honneth 2001: 43). Of course, as key recognition theorist Axel Honneth notes, the concept of recognition is not new; indeed, he suggest that it has always, in one form or another, played a central role in moral-practical philosophy. Indeed, it is Hegel who is widely recognized as the 'lone initiator' - the thinker who placed the principle of recognition at the core of his ethics, and who is undisputed 'father' of contemporary theories of recognition. Specifically, his differentiation between family, civil society and state reflects his distinction between and articulation of three forms of recognition widely used by contemporary theorists of recognition: love, esteem and respect (Honneth 2001: 47-8).

Although there is very little existing work that treats the two concepts or literatures together, there are a number of affinities and points of intersection between the ethics of care and the ethics of recognition. Perhaps most importantly, care and recognition highlight relations between moral subjects: acts or practices of care and recognition can only occur in relation. That said, in the ethics of care, it is the relation itself, and the responses and responsibilities that flow from it, which are of both ontological and normative significance. In the theory of recognition, however, what matters is the effect or outcome of the relation on the individuals; in other words, that the effect of a given relationship is such that the individuals involved feel loved, esteemed or respected in the eyes of the other.

As Carol Gould has pointed out, Honneth implicitly links recognition to care. As Gould explains, one of Honneth's three forms of recognition is 'love', which for him includes the caring activities involved in child raising (Gould 2008: 92). The other types of recognition - respect and esteem - combine with love to form a total account of recognition. Notably, these three types of recognition are achieved and upheld in separate spheres: the home and family, the formal institutions of the law and within one's 'career' (Gould 2008: 99).

The inclusion of 'love' and 'caring activities' in an ethics of recognition, however, does not necessarily entail a political commitment to feminist goals. As Julie Connolly (2010) points out, although Honneth asserts the need for love-based recognition, emerging out of relations of nurturance, he also argues 
that relations encompassed by this category are 'pre-political. This serves to reinforce the public-private distinction, and therefore to marginalize feminist concerns with how power functions through recognition in the private sphere. This is in marked contrast to most feminist work on care ethics, which seeks explicitly to challenge the public-private dichotomy - specifically, the assertion that care matters only in the context of intimate, personal relationships but that it is irrelevant, or even dangerous, in the 'public' realm. Challenging this account within ethics is part of a wider feminist contestation of what counts as 'the political' and how these assumptions are fundamentally constituted through historically constructed gender norms, rules and power relations.

In her analysis of the ethics of care and recognition, Gould employs a distinction between 'rigorous recognition' and 'generous recognition' (she also uses the terms 'empathic' recognition and 'solidaristic' recognition) in order to highlight the way that the latter sort of recognition embodies a 'caring attitude towards others' (2008: 99). This latter type of recognition includes a more 'feelingful (as well as cognitive) understanding of the distinctiveness of others in their concrete circumstances and the difficulties they face, along with an acknowledgment and appreciation of their agency in that context' (Gould 2008: 99). In this sense, we can imagine how the ethics of care might intersect with the ethics of recognition; both involve an assurance to the other that 'I see you and I am listening to you'.

Thus, both the ethics of care and recognition are premised on the relationship between moral agents, and both assert the importance of attentiveness to particular others. But while care ethics focuses on interdependence, shared vulnerability and human frailty within a normative framework of attentiveness to the needs of particular others, recognition theory is oriented towards the affirmation of individual and group identities and differences. In other words, while care ethics focuses on attentiveness as a method of addressing that other's distinctive needs, recognition stresses attentiveness as a method of affirming the distinctiveness itself (usually the 'cultural' distinctiveness) of that other, either as an individual or as a group.

\section{Recognition and 'the international'}

In the dominant (realist) strands of International Relations (IR) theory, international politics is understood as the relations among sovereign states. The modern state system is said to be unique in that its members recognize 
one another as equal authority claimants. Each is recognized as having the final and exclusive authority to use coercion within its territorial borders (Thomson 1995: 219). Thus, as Onuf (2013: 122) explains, insofar as scholars in IR think about recognition at all, we take it to be a legal condition - one that is well established in state practice and legal theory. But as Janice Thomson (1995: 219-20) has pointed out, while theoretical and empirical work persuasively demonstrates the crucial role external recognition plays in constituting state sovereignty, it remains unclear just who must do the recognizing: a majority of states, the Great Powers, all states, a core of elites, a hegemonic power or something else.

Given the narrowness of the 'international law' conception of recognition, it is perhaps not surprising that the past decade has witnessed the growth of what has been called an 'international political sociology' approach, which has been used to explain 'actor identities, the change and continuity of international social structures, the emotional needs of, and policy decisions by, international actors' (Agne et al. 2013: 95). This approach has been described as the 'constitutive' theory of recognition, defended and developed in the contemporary debate by constructivist IR theorists (Erman 2013: 130). Thus, theories of recognition in International Relations have tended to focus on either the declarations of formallegal recognition of sovereign states by other states, or the practices of recognition that are constitutive of actors' identities in international politics.

The idea of moral recognition, however, has received comparatively less attention in International Relations. Bartelson argues that, in the international realm, moral recognition takes us beyond the mere recognition of rights, and into the thick recognition of social and cultural identities. Axel Honneth has recently addressed the idea of recognition in international relations, arguing that 'the path for civilizing international relations primarily lies in sustained efforts at conveying respect and esteem for the collective identity of other countries' (Honneth 2012: 149).

It is worth asking, however, what this would mean in practice. First, what people or organizations are supposed to engage in these 'sustained efforts'? While it is rarely articulated explicitly, there is little doubt that this model of recognition in IR presumes that 'the West' - the club of industrialized, incomerich states that make up the already-civilized world - are the actors who are supposed to make these efforts to recognize the collective identities of peoples in 'Other' countries. But why should they make such efforts? What mechanisms are in place, or could be put in place, to motivate this recognition? Why should we assume that the process of recognition will actually result in an affirmation 
of the distinctiveness and legitimacy of another state or culture, rather than a rejection?

Bartelson is worth quoting at length here:

Since recognition in the sense of acknowledgement presupposes a prior identification of the actor to be recognized, and since such identification in turn presupposes the possibility of distinguishing those actors that are fit for recognition from those who are not, actual practices of recognition will always depend on underlying schemes of classification. Since these schemes are historically variable and culturally contingent, the practices of political, legal, and moral recognition have also conditioned the differentiation between the European states system and its non-European outside.

Thus, from a postcolonial perspective, the practices of political, legal and moral recognition look like little but advanced forms of back-scratching, through which Western powers have secured their dominance over the rest of the world by excluding those entities that do not conform to the Western state form, or to Western standards of civilization, from consideration as legal and moral equals. (Bartelson 2013: 121, 123)

Recognition in international politics also risks becoming an act of productive power, whereby the bestowing of recognition becomes construction of the other as 'Other' - in other words, an act of 'Orientalizing. Identifying 'cultural groups' to be recognized serves to reify and re-present those groups and their 'cultures'. Tony Evans (2011: 1753) addresses this issue in the context of Islam, arguing that Islam is presented in European and North American societies as a 'monolithic, proselytising creed dedicated to undermining, overturning, and eventually replacing the values that have sustained capital growth on a global scale'

\section{Paternalism in globalized care and recognition}

Can we act responsibly towards others without undercutting their autonomy and freedom?

(Inayatullah 2013: 452)

Much ink has (rightly) been spilled describing the paternalistic impulses and effects of European rationalism on so-called 'non-Western' cultures. The globalist and narcissistic tendencies of Western liberalism are inextricably linked to the paternalism that justified 'civilizing missions' around the world, and continue to justify various kinds of 'humanitarian' intervention in the lives of others today. 
Spreading 'our values' - through the promotion of democracy, the enactment of the 'Responsibility to Protect', or discourses of 'end poverty' campaigns - is often undertaken not only under the guise of care but under the guise of liberation.

And yet, a tension exists within liberalism, especially in the context of the international. Despite the obvious role of liberalism in justifying interference in the lives of others, liberals can be credited, as Barnett argues, with 'making paternalism something of a sin'. Using Gerald Dworkin's definition, we can understand paternalism as 'the interference with a person's liberty of action justified by reasons referring exclusively to the welfare, good, happiness, needs and interests or values of the person being coerced' (Dworkin, quoted in Barnett 2013: 487). Although paternalism 'violates nearly every cherished principle of liberalism, liberals are able to aggressively promote their own ideology without appearing to be guilty of paternalism (Barnett 2013: 492). But it is only through a remarkable sleight of hand that liberalism has been used by the powerful to make this tension disappear. In arguing that liberal principles are deontic principles - principles of right or 'regulative' principles which specify the terms and constraints under which substantive goods may be promoted and pursued liberals are able to manage the contradictions between 'liberty' and 'paternalism'. In other words, they are able to argue that the promotion of liberalism globally is not interference or domination or 'telling others what is good for them'; rather, it is simply providing them with the freedom to decide for themselves. What critics like Evans and others have shown, however, is that liberalism effectively narrows the range of permissible conceptions of the good in ways that must be defended not merely as just but also as good (Smith 1996: 254). In the context of the international system, Barnett (2013: 490) notes the way that liberalism's individualistic ontology leads to a 'neglect of the underlying social relations that generates the positions of superiority and inferiority and a sense of noblesse oblige'.

In contrast to the ubiquitous and well-founded critiques of liberalism, critical scholars have not worried too much about the paternalistic implications of international activities justified by the language of 'caring. Perhaps it is because we are already cynical about 'care' in international relations - perhaps we think we already know that anyone who purports to 'care' in the context of international politics doesn't really do so, but is instead using that language to mask aims of domination, self-interest or self-aggrandisement. Barnett suggests that contemporary humanitarianism is constituted by both compassion and care on one hand, and command and control on the other (Barnett 2011: 105). On his view, however, this is not necessarily cause for concern. Indeed, Barnett argues that it is neither possible nor necessarily desirable to remove paternalism from 
the international humanitarian order; rather, he sees it as a latent or manifest feature of all relations of compassion (Barnett 2011: 128). Ultimately, he argues, the challenge is to discern when it is justifiable that actors should interfere in the lives of others because it will be for their own good, and when it is not (Barnett 2011: 105). The problem with this solution, as I see it, is that it leaves intact the underlying structures and norms which position some individuals and states as 'carers' - with responsibilities to protect, develop or educate - and others as 'receivers of care'.

How can we escape this paternalism that appears to be so deeply embedded in both the ethics of care and the ethics of recognition in the context of liberal internationalism? Is it sufficient simply to supplement care ethics with an ethics of recognition? One way of looking at this problem is to ask whether a global ethic of care is really about a powerful and benevolent 'West' caring about the vulnerable, needy and poor in developing countries? Elsewhere I have argued that a global ethic of care cannot be understood as a normative injunction to 'care for' distant others; rather, it should be seen as a critical theory that reveals the extent and scope of caring activities around the world in an effort to demonstrate both the importance of caring activities for the survival and security of all human beings, and the ways in which caring practices are governed by gendered, classed and racialized relations of power (Robinson 2011).

But while this approach may present a more critical vision for care ethics and one that has the advantage of paying attention to unequal relations of gender, class and race at multiple scales - it cannot escape the fact that rhetoric and narratives of care are widely used to justify paternalistic acts, and also that the ethics of care is usually understood in its strongly normative sense. ${ }^{1}$ In the section that follows, I try to map out a blueprint for strategies of transformative recognition that can help us to avoid the 'dark side of care'.

\section{Transformative recognition and a global ethic of care}

In her rich and insightful book Care in Everyday Life, Marian Barnes discusses the 'categorical separation of care receivers from care givers and the assumptions of a different moral weight attached to these two distinct identities' in the context of the disability movement. As Barnes argues, it is neither empirically accurate nor morally defensible - in this context and in others - to define people as only givers or receivers of care. She insists that the 'political argument needs to be about care and the necessity and value of care, rather than the comparative merits 
of protecting the rights and interests of those who are currently "dependent" or “independent”' (Barnes 2012: 178).

This is a very powerful argument. It suggests that the some of the normative and transformative power of an ethics of care is located not in the caring as such. The act of bestowing care on another, while it may appear 'morally good' in a conventional or superficial manner, is actually fraught with possibilities for damaging self-sacrifice on one hand and paternalistic domination on the other. What is important about care is its necessity - it must be done; and its ubiquity it is always being done. The political task is revealing and defending the ways and extent to which practices of care sustain life that is physically comfortable and emotionally secure. This also involves addressing the historical and contemporary institutional conditions and structures that define relations of care in a variety of contexts and across multiple scales. This, in turn, leads to the task of setting out the conditions under which practices of care can be carried out under conditions that avoid domination, self-sacrifice and harm, or exploitation.

This chapter asks how relations and practices of 'globalized care' can avoid the harms of paternalism. I am suggesting that care must involve recognition of the other, but that this recognition can be achieved only through strategies that are 'transformative' of the conditions under which roles of 'carer' and 'cared for' are constructed, edified and performed. The point of transformative strategies of recognition is that they redress disrespect by transforming the underlying cultural-valuational structure. As Fraser (1995: 83) explains, by 'destabilizing existing group identities and differentiations, these remedies would not only raise the esteem of members of currently disrespected groups. They would change everyone's sense of belonging, affiliation and self'. Efforts to 'develop' the poor, whether framed in the language of care or justice, generally presuppose what Fraser calls a 'universalist conception of recognition, the equal moral worth of persons'. But as she points out, as iterated over time, practices of 'affirmative redistribution' tend to set in motion a second, stigmatizing, recognition dynamic, which contradicts universalism (Fraser 1995: 85).

Critical and postcolonial theorists in International Relations and international political theory have sought to reveal the effects of this dyadic structure in the context of North-South relations and 'global justice'. Peggy Kohn (2013: 194) argues that the 'normative argument that the rich have an obligation to help the global poor is convincing, but the rhetorical structure reinforces a hierarchical relationship. Franziska Dubgen (2012: 69) describes 'Africa Humiliated', referring to tacit and overt forms of misrecognition within the practice of development aid. As she explains, development aid's hegemonic image represents itself as a gesture 
of generosity while at the same time it serves to sustain the status quo, effectively affirming existing power hierarchies (Dubgen 2012: 83). In her powerful novel Americanah, author Chimamada Ngozi Adichie describes a scene in which the Nigerian heroine, Ifemelu, attends a party held by the wealthy white American family for whom Ifemelu works as a nanny. Ifemelu endures the guests' sweeping generalizations about 'Africa', including descriptions of the charitable work in which they are engaged:

Two women spoke about their donations to a wonderful charity in Malawi that built wells, a wonderful orphanage in Botswana, a wonderful microfinance cooperative in Kenya.... Ifemelu wanted, suddenly and desperately, to be from the country of people who gave and not those who received, to be one of those who had and could therefore bask in the grace of having given, to be among those who could afford copious pity and empathy. (Adichie 2013: 209)

As these accounts suggest, there can be no positive change until this dichotomy of self-righteousness and humiliation is disrupted. The first step in this direction is to challenge the image of care as a dyad between caregiver and care receiver. As Tronto points out, this image is not only inaccurate, it has bad consequences. Indeed, it begins to 'import into the very nature of care its inequality' (Tronto 2013: 152-3). It obscures the fact that caregivers too are vulnerable, needy and sometimes incompetent. And it can serve as a justification for continuing to exclude and not think about care receivers and their close caregivers as full, participating citizens (Tronto 2013: 152-3). Just as Tronto argues in the context of caring democracy, the undermining of the hierarchical logic of care as dyadic is the first step towards developing non-paternalistic globalized care. As Mark Duffield (2007: 233) suggests, there must be an emphasis on 'mutuality and reciprocity between provider and beneficiary while blurring the differences between them'. What is required, he argues, is a 'change of comportment' instead of educating (or 'caring for') the poor and marginalized, there needs to be an openness to learn from their struggles (Duffield 2007: 233-4).

While I cannot, in this chapter, offer a fully developed account of transformative recognition for global care ethics, I would argue that the key to such strategies lies in the politics of representation. Consider, for example, the website and associated songs and videos, 'Radi-Aid: Africa for Norway'. Created by the Norwegian Students and Academics International Assistance Fund, SAIH, the website, songs and videos parody familiar tropes in Western humanitarianism - from 'end poverty' pop songs and videos, to 'save the children' television advertisements. As one of the creators explains, 'Paternalistic 
narratives of Africa as a starving, hopeless and most recently rising continent continue to reinforce its stereotypical perception as an economic backwater replete with tribal conflicts and always in need of Western intervention. For charities, the images of starving and lonely African children established the norm for NGO fundraising' (Olav Edland-Gryt 2014). While the 'Africa for Norway' music video does not really aim to suggest that freezing Norwegians really need help from Africans (by providing heaters), it does render laughable the idea that the generous-hearted and caring people of the (cold) North can help 'Africans' by donating money. As Olav Edland-Gryt explains, comedy can turn the tables on how we see development in Africa, shifting the focus from the less privileged to the privileged, shedding light on the role of the 'white-savior industrial complex' (Olav Edland-Gryt 2014). By 'turning the tables', 'we' in the global North are compelled to rethink the implications of our 'moral' actions. The result is that we cannot look at them with pity; instead, we are able to see their agency, and contrast their clever satire with our own puffed-up and pathetic gestures. It invites reflection on whether our 'care' is effective, and on the attitudes to and organization of care in our own wealthy and 'comfortable' societies. Moreover, it compels us to reflect on the harm we may be doing in 'doing good'.

The objection could be raised here that an initiative like this is still a creation of the West, and not a direct challenge by those who suffer at the hands of paternalistic caring. Indeed, Narayan suggests that political contestations and moral challenges must come from those who are constructed as the objects of care: 'It seems to me that what such ideological pictures often yield to are not primarily theoretical moral self-corrections, based either on reason or on enlarged sympathies with Others, but to political contestations and moral challenges by groups who are victimized by the status quo' (Narayan 1995: 137). That said, it can also be argued that it is not the duty of the oppressed to educate the oppressor. The effects of transformative recognition should not be, as Shilliam (2013b: 141) argues, to 'shock and awe', or 'break down' the powerful with guilt so as to ultimately build them up again.

At the other end of the spectrum from comic satire lies the tragedy of war. In his short but thought-provoking 2009 article, Tarak Barkawi describes the disordering effect of great Western powers' so-called 'small wars':

What 'small wars' have the potential to unhinge are the archetypes by which the West comes to be the West. Westerners discover they are not liberators, but oppressors, not developers but destroyers, not civilized but barbaric: they discover to their horror, and despite all their electronic gadgetry, that they are 
not smarter than their enemies, but stupid and lumbering;... most of all, they discover, despite their impressive legions and their fearsome armaments, that they are not strong. (Barkawi 2009: 129)

Such wars, Barkawi explains, involve enormous and seemingly secure identity investments in the weak, who despite all manage to turn the tables on the West. Interestingly, Barkawi describes how the response to such a 'loss' could go in one of three ways: a return to isolationism, righteous 'total war' set off by 'Orientalist panic'. It is the third scenario on which the possibility of transformation relies - the inspiration of 'a degree of self-doubt, of reflection and reflexivity, of questioning of authority, willingness to accept responsibility' (Barkawi 2009: 129).

Of course, no one would advocate engaging in wars as a method for unhinging the dichotomous logics of weak and strong, carers and 'cared for' in the world today. However, the examples above illustrate how both self-conscious parody and real-world 'big events' can unsettle our comfortable pictures of our place in the world - of who is strong and who is weak, who is 'smart' and autonomous, and who is childlike and dependent. The point of 'turning tables' is not to keep them upturned, but ultimately to right them in a way that resists falling back into dichotomous logics, and puts our shared need to give and receive care at the top of the agenda for dialogue.

While Michael Barnett (2013: 518) suggests that the occasional act of paternalism' is preferable to a 'pledge of indifference', I would argue that this stark binary between indifference and paternalistic care obscures the ways and extent to which practices of care can be transformative. In this chapter, I have argued that caring for others in the world must involve explicit strategies of transformative recognition. A global ethics of care cannot simply 'care about' unfortunate, weak or vulnerable others without critical reflection on the historical and contemporary norms, structures and institutions that shaped the positionalities of these caring relationships. Strategies of transformative recognition force us to confront the paternalism inherent in our gestures towards 'global care'. Upending the dichotomous logic of 'carer' and 'cared for' in the world restores a vision of all persons as givers and receivers of care, and focuses attention on strategies for ensuring strong relations and networks of care in societies in all parts of the world.

\section{Note}

1 Michael Barnett $(2011,2013)$ clearly interprets care ethics in this way. 